\title{
Uma Crítica Popperiana ao Raciocínio Sociológico de Jean-Claude Passeron
}

[A Popperian Analisys of Jean-Claude Passeron's Sociological Reasoning]

\section{Sergio Tarbes*}

Resumo: No livro O Raciocínio Sociológico: o espaço não popperiano do raciocínio natural, o sociólogo francês Jean-Claude Passeron afirma que a utilização estrutural de linguagem natural nas ciências sociais cria o que denomina "raciocínio sociológico", um método baseado no raciocínio natural onde não seriam possíveis a "demarcação" e "falseabilidade" de Popper e os "paradigmas" e a "ciência normal" de Kuhn. O presente artigo se propõe a analisar os fundamentos empíricos da afirmação de Passeron por meio de um método inspirado nas ideias de Karl Popper, consistente, no caso, na apresentação de exemplos empíricos que a contradigam. Os resultados permitem concluir que se existem dificuldades nas ciências sociais para a realização de experimentos e para a consolidação de paradigmas, tais dificuldades não podem ser atribuídas à utilização da linguagem natural.

Palavras-chave: Passeron, raciocínio sociológico, ciências sociais, Popper, Kuhn.

Abstract: In the book Le raisonnement sociologique: L'espace nonpoppérien du raisonnement naturel, the French sociologist Jean-Claude Passeron argues that the structural use of natural language in the social sciences creates what he calls "sociological reasoning," a method based on natural reasoning where Popper's "demarcation" and "falsifiability" and Kuhn's "paradigms" and "normal science" would not be possible. This article analyzes the empirical foundations of Passeron's assertion by means of a method inspired by the ideas of Karl Popper, consisting, in this case, in the presentation of empirical examples that contradict it. The results allow us to conclude that if there are difficulties in the social sciences to perform experiments and to consolidate paradigms, such difficulties cannot be attributed to the use of natural language.

Keywords: Passeron, sociological reasoning, social sciences, Popper, Kuhn.

Introdução

O livro O Raciocínio Sociológico - o espaço não-popperiano do raciocínio natural, de Jean-Claude Passeron, é, antes de tudo, um libelo em defesa do valor epistemológico das

${ }^{*}$ Mestre em Filosofia pela Universidade de Brasília. E-mail: sebrat01@gmail.com. 
ciências sociais. Mas a obra também é uma teoria sobre as possibilidades epistemológicas e metodológicas das ciências sociais, em especial as que o autor denomina "históricas" e "gerais": a sociologia, a antropologia e a própria história.

Desenvolvendo a defesa, Passeron afirma que as ciências sociais já são realizadas na única forma em que podem ser realizadas ${ }^{1}$, que quaisquer avanços teóricos ou tecnológicos não alterarão a essência de sua abordagem atual, e que as características de que se revestem as ciências sociais já são finais, e não parte de um processo evolutivo que pode vir a alterar seus métodos e seu alcance.

Desenvolvendo a teoria, o autor expõe sua visão sobre as características essenciais das ciências sociais, em virtude das quais é possível identificar suas diferenças frente às ciências naturais e estabelecer seu método específico. Passeron afirma que as ciências sociais utilizam a linguagem natural, diferentemente das ciên- cias naturais que utilizam extensamente linguagens artificiais ${ }^{2}$, e que o objeto das ciências sociais insere-se sempre em um contexto histórico, delimitado no tempo e no espaço, que jamais se repete com todas suas características e variáveis em outro local ou outro momento, em tudo diferente do objeto das ciências naturais. Essas duas características - linguagem natural e contexto histórico - combinam-se para criar o que Passeron denomina de "raciocínio sociológico" ou "raciocínio natural": uma forma de explicar a realidade histórica e social que se utiliza de conceitos contextualizados, metáforas e comparações metodologicamente controladas, e vulnerabilidade empírica fundada em observações amplas e sistematizadas, mas válidas apenas em determinados contextos espaço-temporais.

Com isso Passeron afirma existir nas ciências sociais um espaço não-popperiano, ou seja, uma área do conhecimento humano onde os pontos centrais da filosofia das ci-

\footnotetext{
${ }^{1}$ Em relação ao aspecto que interessa ao presente artigo, essa única forma diz respeito à utilização privilegiada de linguagens naturais nas ciências sociais.

2Ainda que seja questionável a utilização das expressões "língua artificial" ou "linguagem artificial", em referência aos sistemas formais, ou sistemas simbólicos, como a matemática, a geometria e a lógica, elas foram mantidas por duas razões principais: primeiro, porque são as expressões utilizadas por Passeron no texto sob análise (vide PASSERON, 1995, p. 470), e, segundo, porque estabelecem uma dicotomia, bastante interessante para os objetivos do presente trabalho, com as expressões "língua natural" e "linguagem natural", também utilizadas por Passeron. As línguas ou linguagens naturais seriam aquelas utilizadas pelo ser humano em sua comunicação usual com outros seres humanos e por meio da qual são eles capazes de realizar descrições sobre o mundo que os cerca e narrativas sobre as experiências vividas ou observadas. Essa explicação sucinta é suficiente para que o leitor possa compreender a argumentação apresentada no presente artigo.
} 
ências de Karl Popper - mas ao final, e por outras razões, também de Thomas Kuhn ${ }^{3}$ - não teriam aplicação. Nesse sentido, não se aplicariam às ciências sociais a "demarcação" e a "falseabilidade" de Popper ${ }^{4}$ e os "paradigmas" e a "ciência normal" de Kuhn" ${ }^{5}$, ideias essas que ambos os filósofos afirmaram ser aplicáveis a todas as ciências ${ }^{6}$.

Caso Passeron esteja certo, a sociologia já teria atingido sua maturidade com uma abordagem específica das ciências sociais históricas - consistente no "raciocínio natural" ou "raciocínio sociológico" -, o que afastaria em definitivo a hipótese de unicidade do método científico e posicionaria o âmbito de validade das ideias de Popper e Kuhn apenas nas ciências naturais.

Não se pode afirmar que a posição defendida pelo autor francês por ele construída ao longo da década de 1980 -, tenha prevalecido. Conforme apontado por Roberto
M. Ferreira “(...) desde os anos 90 vem crescendo o número de autores que, talvez descontentes com os resultados do interpretive turn, voltaram a defender a possibilidade do unitarismo metodológico", o que "implica recusar a suposta especificidade epistemológica do objeto das ciências sociais" (FERREIRA, 2008: 19).

$O$ presente artigo insere-se nesse debate, qual seja, em termos amplos, sobre as especificidades dos métodos a serem utilizados nas ciências sociais em relação àqueles utilizáveis nas ciências naturais, e, em termos específicos, sobre a validade das referidas afirmações e Popper e Kuhn para as ciências sociais.

Estabelecida a oposição específica entre as ideias de Passeron e as de Popper e Kuhn, este trabalho se propõe a analisar um dos pilares da tese de Passeron. Extrai-se do texto de Passeron que o "raciocínio sociológico" é moldado a partir de duas características prin-

\footnotetext{
${ }^{3} \mathrm{O}$ debate entre Karl Popper e Thomas Kuhn é amplo, não cabendo aqui revisitá-lo. As razões pelas quais as teses de Passeron se opõem a ambos será esclarecida ao longo do presente artigo.

${ }^{4} \mathrm{O}$ próprio Popper parece concordar com essa afirmação de Passeron, uma vez que propôs dois métodos específicos para as ciências sociais, a análise situacional e a engenharia social de ação gradual, bastante diferentes do método por ele proposto para as ciências naturais, decorrente da demarcação. Não obstante, as razões popperianas para tanto são bem diferentes daquelas apresentadas por Passeron. O presente artigo analisa um conjunto específico de razões apresentado por Passeron.

${ }^{5}$ Kuhn também parece concordar com essa afirmação de Passeron, mas a razão para tanto advém de uma discordância entre ambos: Kuhn acreditava que as ciências sociais não tinham se desenvolvido integralmente, e apenas por essa razão não tinham ainda atingido o estágio paradigmático e de ciência normal. Como já afirmado na nota anterior, o presente artigo analisa um conjunto específico de razões apresentado por Passeron.

${ }^{6}$ Exemplos dessas afirmações podem ser encontrados em POPPER, 2007, p. 35 ("denomino problema de demarcação o problema de estabelecer um critério que nos habilite a distinguir entre as ciências empíricas, de uma parte, e a Matemática e a Lógica, bem como os sistemas 'metafísicos', de outra") e KUHN, 2009, p. 31 (“a aquisição de um paradigma (...) é um sinal de maturidade de qualquer campo científico”).
} 
cipais. A primeira, a de necessariamente ser construído em linguagem natural. A segunda, a de necessariamente referir-se a objetos inseridos em contextos delimitados espacial e temporalmente (históricos). A argumentação aqui desenvolvida restringe-se a analisar o primeiro desses aspectos, em especial algumas das consequências que Passeron afirma advirem da utilização da linguagem natural nas ciências sociais.

\section{Sobre a possibilidade de crítica das proposições de Passeron por meio da refutação empírica}

Uma vez que Passeron pretendeu excluir Popper e Kuhn do jogo das ciências sociais, nada mais justo que se utilize os argumentos de pelo menos um deles para tentar fazer com que ambos retornem. Para tanto, a opção metodológica de análise e crítica das teses de Passeron, relativas às consequências da utilização da linguagem natural pelas ciências sociais, será inspirada nas ideias popperianas de refutação empírica, conforme sucintamente descrito adiante.

A construção do autor francês é filosófica - um exercício crítico a ser examinado e criticado e não a ser refutado -, e, portanto, talvez não seja de todo correto utilizar, a título de instrumento de crítica, um método criado para teste de teorias científicas. Por outro lado, e ao construir suas proposições, Passeron aparentemente atravessou a tênue fronteira entre asserções metafísicas e asserções empíricas. Se isso é verdade, como se tentará demonstrar mais adiante, suas proposições passam a ser empiricamente criticáveis.

Em outras palavras, e como será detalhadamente descrito a seguir, é a forma lógica sob a qual foram redigidas grande parte das proposições apresentadas por Passeron que permite que o método de refutação empírica aqui utilizado, inspirado nas ideias de Popper, seja a elas aplicável. Assim, o que torna possível criticar empiricamente as proposições apresentadas por Passeron, não reside no entendimento de serem "científicas" ou de o autor tê-las construído com essa intenção, e também não depende dos conceitos de teoria científica ou de explicação científica construídos por Popper, mas sim do fato de serem logica e empiricamente refutáveis.

O método de refutação empírica popperiano pode ser logicamente descrito (ou encontra-se logicamente fundamentado) por meio do modus tollens da seguinte forma (POPPER, 2007, p. 80):

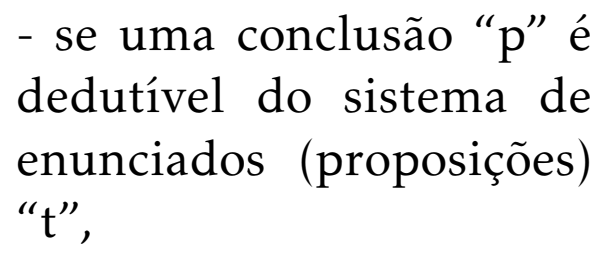
dedutível do sistema de enunciados (proposições) " $\mathrm{t}$ ", 
- e se "p" revela-se falsa,

- então " $t$ " será necessari-

amente falso.

Para avançar em nossa análise crítica sobre as proposições de Passeron torna-se necessário, então, deduzir consequências de suas proposições. Pela restrição estabelecida ao escopo do presente trabalho, devem ser analisadas consequências relacionadas exclusivamente à utilização de linguagem natural pelas ciências sociais.

A primeira dessas consequências pode ser extraída diretamente da Proposição 1: "As ciências empíricas são linguagens de descrição do mundo que devem produzir um tipo particular de conhecimento com as provas empíricas que a estrutura lógica dessas linguagens torna possíveis e necessárias" (PASSERON, 1995, p. 400). Se, conforme afirma Passeron, "as ciências empíricas são linguagens de descrição do mundo" e se essas linguagens produzem "um tipo particular de conhecimento" advindo "da estrutura lógica dessas linguagens", o que determinaria, inclusive, as provas empíricas possíveis em seu âmbito, então é porque cada ciência tem suas provas empíricas, sua linguagem $e$ seu tipo de conhecimento específicos (primeira consequência).

A segunda dessas consequên- cias pode ser extraída da combinação de subproposições das Proposições 1, já referida, e 2: "Não existe e não pode existir linguagem protocolar unificada da descrição empírica do mundo histórico" (PASSERON, 1995, p. 405), quais sejam, a proposição 2.4: "A sociologia, assim como a história ou a antropologia, em seus enunciados finais, só se pode falar em língua natural" (PASSERON, 1995, p. 422), a proposição 1.2.1: "Um alto grau de consenso realizado num grupo de especialistas e relacionado a um alto grau de estabilização de uma linguagem de descrição do mundo define um 'paradigma' científico" (PASSERON, 1995, p. 403) e a proposição 2.1: "A sociologia não toma e nem pode tomar a forma de um saber cumulativo, isso é, um saber cujos conhecimentos acumulados fossem organizados por um paradigma teórico" (PASSERON, 1995, p. 407). Assim, se cada ciência tem sua linguagem específica (já referida proposição 1), se a linguagem específica da sociologia é a linguagem natural (proposição 2.4), se apenas um "alto grau de consenso realizado num grupo de especialistas", consenso esse dependente de "um alto grau de estabilização de uma linguagem", torna possível a definição de um paradigma científico (proposição 1.2.1), e se a "sociologia não (...) 
pode tomar a forma de um saber cumulativo" organizado "por um paradigma teórico" (proposição 2.1), então é porque a linguagem natural, sempre "instável", impede a estabilização da linguagem científica e, consequentemente, a constituição de "paradigmas", a realização de ciência normal e a acumulação de conhecimentos científicos (segunda consequência).

A terceira e última consequência pode ser extraída da combinação das Proposições 1, já referida, e 3: "A prova empírica de uma proposição teórica jamais pode em sociologia revestir-se da forma lógica da 'refutação' ('falsificação') no sentido popperiano" (PASSERON, 1195, p. 426) com subproposições da proposição 2, quais sejam a já referida proposição 2.4 e a proposição 2.2: "A vulnerabilidade e, portanto, a pertinência empíricas dos enunciados sociológicos não podem ser definidos a não ser numa situação de levantamento parcial da informação sobre o mundo que é o da observação histórica - jamais a da experimentação" (PASSERON, 1995, p. 409). Assim, se os tipos de prova empírica a serem utilizados em uma dada ciência são determinados pela linguagem nela utilizada e respectiva estrutura lógica (proposição 1), se "a sociologia (...) só se pode falar em língua natural" (proposição 2.4), se "a pertinência empírica dos enunciados sociológicos" só pode ser realizada por meio de "observação (...) jamais da experimentação" (proposição 2.2), e se "a prova empírica de uma proposição teórica(...) em sociologia" não pode "revestir-se da forma lógica da 'refutação' ('falsificação') no sentido popperiano" (proposição 3), então é porque a utilização de linguagem natural em uma dada ciência impede a realização de observação e de experimentos falseadores no sentido popperiano (terceira consequência).

Esclarecido como se dá a refutação empírica em sua estrutura lógica e a forma como foram deduzidas da teoria de Passeron as três consequências que são aqui submetidas à crítica, resta esclarecer como essas consequências serão efetivamente submetidas ao confronto empírico ${ }^{7}$.

Quase todas as proposições de Passeron expressam impossibilidades existenciais, uma vez que

\footnotetext{
${ }^{7}$ Por confronto empírico quer-se aqui dizer a busca de uma ocorrência no mundo real declarada impossível pela consequência decorrente das proposições de Passeron. Caso encontrada essa ocorrência, então terá ocorrido a refutação. O método lógico-empírico aqui utilizado funda-se, como já salientado, nas ideias de Popper, cujos aspectos essenciais estão aqui sendo observados: a dedução de consequências a partir de um sistema de proposições; a possibilidade de descrição prévia, em abstrato, de uma ou mais ocorrências que refutem essas consequências; a observação ou verificação, em concreto, da ocorrência refutadora prevista em abstrato; e a possibilidade de a observação dessa ocorrência ser reproduzível.
} 
construídas com expressões como "jamais" (proposição 1.1, 2.2, 3, 3.1.1), "nenhum" ou "nenhuma" (proposição 1.1.1, 3.1), "não existe e não pode existir" (proposição 2), "não toma nem pode tomar" (proposição 2.1), "não podem" e "não pode" (proposição 2.2, 2.2.1, 2.2.2), "só pode" - no sentido de "não pode ser diferente de" (proposição $2.2 .3,2.4)$, "não passível de" (proposição 2.3), ou "devem ser sempre" - no sentido de "não podem deixar de ser" (proposição 2.4.1) (PASSERON, 1995, pp. 400 a 461). Pode-se afirmar, portanto, que as proposições de Passeron são construídas sob a forma de negativas de enunciados estritamente existenciais, na forma genérica "não há e não haverá ...”. A já referida proposição 2.1, por exemplo, pode ser escrita na forma "não há e não haverá saber acumulativo na sociologia organizado por um paradigma teórico".

Analisando logicamente os enunciados universais, Popper havia concluído que são equivalentes a negações de enunciados estritamente existenciais, ou seja, que a todo enunciado universal corresponde uma negativa de enunciado estritamente existencial de sentido lógico equivalente, e vice-versa (POPPER, 2009, p. 72). Com efeito, é fácil perceber que expressões do tipo "não toma nem pode tomar", extraída da referida proposição 2.1, expressam um enunciado universal. O enunciado "todos os cisnes são brancos" pode ser escrito sob a forma "um cisne não toma e não pode tomar uma cor diferente de branco".

Popper explica que ambos os tipos de enunciado, estritamente universais e negativas de estritamente existenciais, "precisamente por agirem" no sentido da "não existência de certas coisas ou estados de coisas, proscrevendo ou proibindo, por assim dizer, essas coisas ou estados de coisas", tornam-se logicamente refutáveis por um enunciado existencial singular (POPPER, 2009, p. 72). Empiricamente, a proibição de que existam cisnes de cores diferentes de branco pode ser falseada pela simples apresentação de um cisne de qualquer outra cor, apresentação essa que pode ser expressa sob a forma de enunciados existenciais singulares, como, por exemplo, "eis aqui um cisne negro" 8 .

Assim como as proposições, as consequências delas deduzidas também são negativas de enunciados estritamente existenciais,

\footnotetext{
${ }^{8} \mathrm{O}$ método de refutação empírica aqui utilizado não requer a realização de experimentos dirigidos por proposições que se pretenda refutar. Observações dirigidas pelas proposições que se pretende refutar detém igual valor, tanto lógico quanto empírico. Isso é totalmente compatível com as ideias de Popper que inspiram a forma de análise aqui utilizada.
} 
de onde decorre que para refutar uma consequência se faz necessário contrapor um enunciado existencial singular. Desse modo, no intuito de testar a pertinência empírica das consequências das proposições de Passeron, que proíbem determinadas ocorrências, serão apresentados exemplos que demonstrem já terem efetivamente ocorrido consequências que as proposições afirmam serem impossíveis.

\section{Sobre a utilização de linguagens nas diversas ciências}

Passeron afirma que cada ciência tem uma linguagem que lhe é característica, da qual decorrem necessariamente o tipo de conhecimento produzido naquela ciência e o tipo de prova empírica nela utilizado, ou seja, que cada ciência tem sua linguagem, seu tipo de conhecimento e suas provas empíricas específicas.

Ao longo de todo o seu texto, o autor atribui às ciências naturais características muito específicas das ciências formais e da física, segundo ele consequências necessárias da utilização de linguagens artificiais, e atribui às ciências sociais características específicas da história, segundo ele consequências necessárias da utilização de linguagem natural ${ }^{9}$, e nesse contexto dicotômico desenvolve sua argumentação.

Objetivando apreciar a pertinência empírica da afirmação do autor francês faz-se necessário escapar desse posicionamento dicotômico estremado, que cria um viés tendente a retirar do campo de análise todas as demais ciências, e apresentar e analisar exemplos de outras ciências, que não as duas referidas, como, por exemplo, a biologia (como ciência natural) e a economia (como ciência social) analisadas a seguir, e a psicologia cognitiva (como ciência humana), analisada mais adiante em outra seção deste artigo.

Com relação às Ciências Biológicas é possível observar que as áreas de conhecimento que tenham relação com a físicoquímica, o metabolismo e a genética detenham avançado grau de utilização de linguagens artificiais na construção do conhecimento a elas relacionado. Por outro lado, o conhecimento relacionado, por exemplo, à patologia e à fisiologia, conforme será visto mais adiante, encontra-se quase que totalmente construído em linguagem

\footnotetext{
${ }^{9}$ Vide nota de rodapé $\mathrm{n}^{\circ} 2$, retro.

${ }^{10}$ As afirmações contidas no parágrafo podem ser constatadas, por exemplo, em ROBBINS \& COTRAN, 2005, e BERNE et al., 2004.
} 
natural ${ }^{10}$. Essas afirmações são válidas para descrições de explicações a respeito de constituição e funcionamento dos seres vivos tanto em zoologia, quanto em botânica, quanto em medicina.

Um aspecto interessante a ser suscitado refere-se ao fato de a Ecologia utilizar a linguagem natural e linguagens artificiais (estatísticas e grafismos geométricos) na descrição dos mais variados meio-ambientes - que dizem respeito ao mundo natural e que, apesar disso, dizem respeito a contextos espaciais diferenciados -, demonstrando a extrema flexibilidade existente na utilização das linguagens pelos cientistas.

O exemplo mais contundente da utilização da linguagem natural nas ciências naturais talvez esteja na Teoria da Evolução - teoria estruturante de toda a biologia contemporânea, que tem ramificações e consequências em praticamente todas as suas subáreas -, que foi integralmente construída em linguagem natural, conforme pode ser facilmente observado no exame do livro $\mathrm{Da}$ Origem das Espécies, de Charles Darwin (DARWIN, 2006).

Dados esses exemplos de utilização de linguagem natural nas ciências naturais, cabe dar exemplo de utilização intensiva, e até mesmo estrutural, de linguagens artificiais nas ciências humanas. Entre essas, a Economia é provavelmente aquela que atingiu maior grau de formalização. São famosas na Microeconomia as curvas que demonstram a análise gráfica das correlações entre diversos conceitos, como por exemplo, as curvas de oferta e demanda e as respectivas regras para o deslocamento dessas curvas, ou para de elasticidade-preço da demanda, ou para demonstrar conceitos como o de receita marginal (FRANK, 2012, pp. 82/82, 103 a 105, 243/244, respectivamente). Não obstante, toda essa análise pode ser também realizada de forma algébrica, evidenciando de forma ainda mais clara proporções e relações quantitativas (FRANK, 2012, pp. 93 e 94). Apesar de essas relações serem mais utilizadas em Microeconomia, esse tipo de formalização e a utilização de gráficos para demonstrar correlações também são largamente utilizados em Macroeconomia, como, por exemplo, curvas de demanda por mão de obra em relação a preços de produtos (FRANK, 2012, pp. 488 e 489).

O melhor exemplo de utilização estrutural de linguagens artificiais nas ciências humanas talvez seja encontrado na Econometria. As várias definições possíveis dessa área do conhecimento remetem à necessidade de "dar su- 
porte empírico aos modelos construídos pela economia matemática", ou de analisar quantitativamente "os fenômenos econômicos concretos, baseada no desenvolvimento simultâneo de teoria e observação, relacionadas por métodos de inferência adequados", de forma que a "econometria pode ser definida como a ciência social na qual as ferramentas da teoria econômica, matemática e inferência estatística são aplicadas à análise dos fenômenos econômicos" (GUJARATI, 2000, Introdução, p. XXVI).

É possível observar, a partir desses exemplos, que as ciências não são linguagens específicas de descrição do mundo, como afirmou Passeron em sua já referida Proposição 1, ou seja, que cada ciência tenha sua linguagem específica ou característica. Modo contrário, os exemplos examinados indicam que as ciências são descrições do mundo realizadas nas diversas linguagens disponíveis, artificiais e natural, que são utilizadas aparentemente a partir das necessidades dos cientistas, da disponibilidade de ferramentas e da compatibilidade entre linguagem e o objeto específico de estudo, entre outros possíveis aspectos.

Com relação à afirmação no sentido de que a predominância de uma ou outra linguagem de- termina o tipo de conhecimento a ser produzido e o tipo de prova a ser utilizada em uma dada ciência, as duas seções seguintes apresentam exemplos de que é possível a constituição de paradigmas, a realização de ciência normal e o acúmulo de conhecimento científico com a utilização exclusiva de linguagem natural e de que é possível, utilizando-se exclusivamente a linguagem natural, construir experimentos diretos ou buscar observações diretas que objetivem promover o já referido confronto empírico.

\section{Sobre a possibilidade de consoli- dação de paradigmas em lingua- gem natural}

Conforme já apontado, Passeron afirma que a linguagem natural, sempre "instável", impede a estabilização da linguagem científica e, consequentemente, a constituição de "paradigmas", a realização de ciência normal e a acumulação de conhecimentos científicos.

Demonstra-se aqui, com pelo menos dois exemplos extraídos da biologia (o segundo deles da medicina, aqui considerada como subárea da biologia), que a utilização de linguagem natural não impede a consolidação de paradigmas.

Em seu livro, A Origem das Espécies, Darwin não utilizou 
linguagens artificiais (DARWIN, 2006, pp. 453 a 760). Toda a teoria foi construída, demonstrada e fundamentada exclusivamente em linguagem natural, e transformou-se no que talvez seja o exemplo de paradigma científico contemporâneo de maior estabilidade e mais ampla aceitação.

Darwin apoiou sua teoria em três pilares empíricos, quais sejam (a) observações por ele realizadas sobre a variedade de animais domésticos provocada intencionalmente pelos criadores por meio da seleção artificial de características desejáveis (DARWIN, 2006, cap. I, pp. 453 a 476), (b) observações por ele realizadas sobre a variedade de animais selvagens, especialmente em sua famosa viagem às Ilhas Galápagos a bordo do Beagle, que ele atribuiu à seleção natural (DARWIN, 2006, caps. II a VIII, pp. 477 a 626), e (c) observações sobre os registros geológicos de fósseis (DARWIN, 2006, caps. IX e X, pp. 627 a 669). A base empírica observacional coletada por Darwin foi suficientemente forte para dar sustentação a sua teoria, a qual foi objeto de reforços posteriores, quer seja por novas observações e pesquisas, quer seja pela evolução de áreas de conhecimento correlatas, como a genética. De qualquer forma, parece não haver dúvidas de que o paradigma criado por Darwin teve influência direta, ou mesmo orientou, boa parte da ciência normal realizada no campo da biologia e, com isso, propiciou um enorme acúmulo de conhecimento, a maior parte do qual produzido em linguagem natural.

Concluindo o raciocínio, sobre a Teoria da Evolução pode-se afirmar duas coisas: primeiro, que nos dias atuais não mais existem cientistas, especialmente biólogos, que questionem seu status científico $^{11}$; e, segundo, que não existem dúvidas no sentido de que a Teoria da Evolução tornou-se um paradigma científico em sentido kuhniano (e é isso o que aqui se discute até esse ponto).

Especificamente sobre a possibilidade de realização de experimentos ou observações em linguagem natural, que atendam o critério popperiano de falseabilidade, é de se reconhecer que experimentos engenhosamente construídos, tanto em laboratórios como o de Richard Lenski, e outros, acompanhando 45 mil gerações de bactéria Escherichia coli, ao longo de 20 anos, e sua evo-

\footnotetext{
${ }^{11}$ Vide, por exemplo, DENNETT, 1995, pp. 18-21

${ }^{12}$ Os resultados dos experimentos de Lenski et al estão descritos em DAWKINS, 2009, pp. 114-130, e foram originalmente publicados em Procedings of the National Academy of Science, $\mathrm{n}^{\circ}$ 91, 1994, pp. 6808-14, apud DAWKINS,
} 
lução frente a contingências ambientais intencionalmente provocadas $^{12}$ - como no próprio ambiente natural (ou ambiente natural restrito) - como os de John Endler com peixes Poecilia reticulata e sua evolução frente a contingências naturais (predadores e alterações ambientais) ${ }^{13}$, sucintamente descritos adiante - vem sistematicamente corroborando consequências dedutíveis da Teoria da Evolução. Com relação a observações falseadoras, o próprio Popper referiu-se ao "melanismo industrial"14 por meio do qual pode-se observar a seleção natural ocorrendo "sob nossos olhos" (POPPER, 1995, p. 242).

Outras áreas da biologia também podem ser consideradas paradigmas kuhnianos. Em medicina, a Patologia, enquanto "estudo das alterações estruturais e funcionais que ocorrem nas células, tecidos e órgãos decorrentes de doenças", ao tempo em que "tenta explicar os motivos dos sinais e sintomas que os pacientes manifestam", fornecendo "uma base racional para a abordagem clínica e o tratamento" (ROB-
BINS \& COTRAN, 2005, p. 4); e a Fisiologia, enquanto descrição "da função dos organismos, nos vários estágios da organização, do nível subcelular ao organismo intacto" (BERNE, 2004, p. xiii); encontram-se quase que totalmente construídas em linguagem natural, o que pode ser observado a partir de manuais utilizados no ensino nas universidades de medicina a respeito da fisiologia e patologias humanas ${ }^{15}$. Ainda que, em termos de Fisiologia, a elucidação dos mecanismos homeostáticos requeira um aprofundamento em bioquímica, e, portanto, a utilização parcial de linguagens artificiais, isso não invalida a afirmação de extensa utilização da linguagem natural nesse campo de conhecimento.

Tais exemplos atendem aos requisitos necessários para serem tidos como "paradigmas" kuhnianos, quais sejam, (a) constituírem um corpo de conhecimento científico coerente, (b) que goze da aceitação da maior parte da comunidade científica, não sendo exigida a unanimidade, (c) que oriente a pesquisa posterior, estabelecendo

\footnotetext{
2009 , p. 417.

${ }^{13}$ Os experimentos de Endler estão descritos em DAWKINS, 2009: 130-136, e foram originalmente publicados nas revistas Evolution, $n^{\circ} 34,1980$, pp. 76-91 e Environmental Biology of Fishes, no 9, 1983, e no livro A Natural Selection in the Wild, Princeton, Princeton University Press, 1986, apud DAWKINS, 2009, pp. 415-416.

${ }^{14}$ Popper refere-se aqui às famosas observações no sentido de que mariposas cor-de-fuligem estariam sendo naturalmente selecionadas, por gozarem de proteção contra predadores fornecida por mimetismo, em áreas urbanas atingidas pela fuligem industrial.

${ }^{15}$ Por exemplo em ROBBINS \& COTRAN, 2005, e BERNE et al., 2004.
} 
o "quebra-cabeças" a ser resolvido, e permitindo assim a ocorrência da "ciência normal", e (d) que, com isso, possibilite o acúmulo de conhecimento científico e o progresso da ciência (KUHN, 2009, Capítulos 1, 2 e 3, e Posfácio: 221 a 227).

A existência desses exemplos, entre outros, leva-nos à conclusão de que a utilização exclusiva de linguagem natural na construção de um corpo de conhecimentos científicos não impede o surgimento de paradigmas, a realização de ciência normal e o acúmulo de conhecimento científico, em sentido kuhniano, contrariando o afirmado por Passeron em suas já referidas proposições.

\section{Sobre a possibilidade de realiza- ção de experimentos em lingua- gem natural}

Conforme apontado, Passeron afirma que a vulnerabilidade empírica de uma ciência que utiliza linguagem natural só pode basearse em observações, enquetes, investigações, etc. e nunca em experimentos intencionalmente realizados.

A contestação empírica de tal afirmação exige que sejam apontados exemplos que demonstrem a possibilidade de idealizar, realizar e descrever experimentos, e posteriormente registrar e publicar seus resultados, exclusivamente em linguagem natural, e que isso já é realizado em diversas ciências. Ainda que Passeron indique a existência de outros fatores que, aliados à utilização de linguagem natural, possam impedir ou dificultar a experimentação direta nas ciências sociais, o que é aqui analisado é a afirmação de que o elemento "linguagem natural”, isoladamente, é suficiente para a produção de tal resultado.

Tomemos como primeiro exemplo o artigo Julgamento sob incerteza: heurísticas e vieses ${ }^{16}$, de autoria de Kahneman e Amos Tversky, ganhadores do prêmio Nobel de Economia de 2012 pelo desenvolvimento de teorias de decisão. Logo ao início do referido artigo os autores apontam que "muitas decisões estão baseadas em crenças relativas à probabilidade de eventos incertos, tais como o resultado de uma eleição, a culpa de um réu ou a futura cotação do dólar", e estabelecem o problema a ser tratado no artigo: "o que determina essas crenças?". Suscintamente respondem logo a seguir, "as pessoas se apoiam em um número limitado de princí-

\footnotetext{
${ }^{16}$ Artigo originalmente publicado na revista Science, vol. 185, 1974, integralmente incluído em KAHNEMAN, 2012, pp. 524 a 539
} 
pios heurísticos que reduzem as tarefas complexas de avaliar probabilidades e predizer valores a operações mais simples de juízo. De um modo geral essas heurísticas são bastante úteis, mas às vezes levam a erros graves e sistemáticos". No corpo do artigo os autores descrevem "três heurísticas que são empregadas para avaliar probabilidades e prever valores", descrições por meio das quais "os vieses aos quais essas heurísticas conduzem são enumerados e as implicações aplicadas e teóricas dessas observações são discutidas" (KAHNEMAN, 2012, pp. 524 e 525).

As três heurísticas analisadas pelos autores são por eles denominadas "representatividade", "disponibilidade" e "ajuste e ancoragem", cujos respectivos vieses são analisados a partir de um ou mais experimentos diretos. Relativamente à primeira heurística, vez que não nos interessa aqui analisar todas elas, os autores analisam os vieses descritos como (a) a insensibilidade das pessoas à probabilidade à priori de resultados, (b) a insensibilidade ao tamanho amostral, (c) concepções errôneas de possibilidades, (d) insensibilidade à previsibilidade, (e) ilusão de validade e (f) concepções errôneas de regressão. Para cada um desses pontos analisados os autores descrevem pelo menos um experimento direto realizado por eles ou por terceiros. Descrever todos os experimentos fugiria ao escopo do presente trabalho, assim, e como exemplo, tomaremos um dos experimentos descritos pelos autores em relação ao viés (b) insensibilidade ao tamanho amostral, o qual envolveu a apresentação a 95 alunos de graduação da seguinte questão (KAHNEMAN, 2012, pp. 526 e 527):

Uma determinada cidade é atendida por dois hospitais. No maior, cerca de 45 bebês nascem todo dia, e no hospital menor nascem cerca de 15 bebês por dia. Como você sabe, cerca de $50 \%$ dos bebês são meninos. Entretanto, a porcentagem exata varia no dia a dia. Às vezes pode ser mais elevada que $50 \%$, às vezes menos. Pelo período de um ano os dois hospitais registraram os dias em que mais do que $60 \%$ dos bebês eram meninos. Qual hospital você acha que registrou mais dias desses?

O hospital maior. (21)

O hospital menor. (21)

Mais ou menos iguais (ou seja, dentro de $5 \%$ um do outro) (53)

Considerando que os valores 
entre parênteses são o número de alunos que escolheram cada resposta, os autores apontam que "a maioria dos participantes julgou a probabilidade de obter mais do que $60 \%$ como sendo a mesma para o hospital pequeno e o grande" a despeito de a teoria da amostragem exigir "que o número esperado de dias em que mais de $60 \%$ dos bebês são meninos é muito maior no pequeno hospital do que no maior, pois uma grande amostra tem menor probabilidade de se afastar de 50\%", a partir do que concluem que "essa noção fundamental de estatística evidentemente não faz parte do repertório intuitivo das pessoas" (KAHNEMAN, 2012, p. 527).

Esse experimento, assim como todos os demais descritos no referido artigo, foi integralmente idealizado, realizado (com exceção de operações estatísticas elementares) e descrito, e posteriormente teve seus resultados registrados e publicados, integralmente em linguagem natural. Trata-se, sem qualquer dúvida, de um experimento direto, e não de uma mera observação sistemática, o qual pode ser reproduzido em qualquer parte do mundo por ou- tros cientistas e por outras instituições utilizando-se de outros grupos amostrais. É fácil observar que a "teoria" dos autores os seres humanos se apoiam em um número limitado de heurísticas para reduzir tarefas complexas de juízo a tarefas mais simples - e seu componente específico - algumas noções fundamentais de estatística, entre elas as decorrentes do tamanho da amostragem, não fazem parte do repertório intuitivo das pessoas -, são empiricamente confrontáveis por esse e por outros experimentos diretos facilmente imagináveis.

Poder-se-ia alegar que, nesse exemplo, a consequência a ser empiricamente refutada não decorre de um enunciado estritamente universal, mas sim de um enunciado numericamente universal, uma vez que o conjunto dos seres humanos seria finito, limitado a determinado espaço, e contável em determinado momento do tempo. Quanto a isso pode-se afirmar que a teoria exposta pelos autores no artigo, conforme descrita no parágrafo imediatamente anterior, tem nítida pretensão de ser universal, no sentido de ser aplicável a todos os seres huma-

\footnotetext{
${ }^{17}$ É o próprio Popper quem afirma que "a questão de saber se as leis da ciência são estritamente ou numericamente universais não pode ser resolvida através da argumentação. Trata-se dessas questões que só podem ser resolvidas por acordo ou convenção". Sua preferência deve-se apenas a ele considerar "útil e frutífero encarar as leis naturais como enunciados sintéticos e estritamente universais", tendo em vista aspectos metodológicos - em POPPER, 2009, cap. 13. Universalidade Estrita e Numérica, pp. 66.
} 
nos, ainda que a totalidade dos seres humanos seja uma universalidade numérica ${ }^{17}$ e que algumas pessoas, em razão de treinamento profissional ou experiência de vida, estejam preparadas para substituir determinadas heurísticas por conhecimento real e, em consequência, evitar determinados vieses. Nesse sentido, Kahnemam aponta que por meio do conjunto de experimentos foram documentados "erros sistemáticos na opinião das pessoas normais" e que ele e Tversky localizaram "esses erros no projeto do mecanismo cognitivo" (KAHNEMAN, 2012, p. 16), mecanismo cognitivo esse pertencente a todos os seres humanos.

Sobre a qualidade científica e impacto do artigo, o próprio autor (KAHNEMAN, 2012, p. 16) acentua que ele "continua sendo um dos trabalhos em ciência social mais amplamente citados (mais de trezentos artigos acadêmicos fizeram referência a ele em 2010)" e que:

(...) estudiosos de outras disciplinas acharamno útil, e as ideias de heurísticas e vieses tem sido utilizadas proveitosamente em inúmeros campos, incluindo diagnósti- cos médicos, análises judiciais, serviços de inteligência e espionagem, filosofia, finanças, estatísticas e estratégia militar. ${ }^{18}$

Como segundo exemplo, agora na área de biologia, o já referido experimento de John Endler a respeito dos efeitos da seleção natural sobre peixes popularmente conhecidos como "guppy", inicialmente publicado por meio do artigo Natural Selection on Color Patterns in Poecilia reticulata (ENDLER, 1980), mostra-se como excelente exemplo de experimento construído em linguagem natural com o objetivo de testar consequências pré-estabelecidas de uma teoria também construída integralmente em linguagem natural, a Teoria da Evolução por meio de Seleção Natural.

Os machos da espécie de peixe selecionada por Endler apresentam fortes e variados padrões de cores, e, apesar disso, foi sistematicamente observado que nos rios onde não havia predadores as cores dos machos eram intensas e onde havia predadores fortes as cores dos machos tendiam a se esmaecer e se tornarem mais próximas em padrão e tonalidade do cascalho existente no fundo. A explicação causal dada pela Teo-

\footnotetext{
${ }^{18}$ Como exemplos de utilização das pesquisas de Kahneman em microeconomia veja FRANK, 2012, Capítulo I, "Três Armadilhas de Decisões Importantes", pp. 8 a 15.
} 
ria, e em consequência sua previsão, é a de que em um ambiente com predação os machos menos vistosos, que se confundam melhor com o cascalho do fundo, tem maior probabilidade de sobrevivência e, portanto, de reprodução, fazendo com que a característica "cores menos vistosas" seja transmitida predominantemente às novas gerações; já em um ambiente sem predadores, a preferência das fêmeas pelos machos mais coloridos, fenômeno observado em várias espécies, levaria a uma seleção para reprodução a partir desse critério, fazendo com que a característica "cores mais vistosas" seja predominantemente transmitida às novas gerações.

Endler concebeu o experimento de forma a confrontar os dois critérios de seleção natural e a testar integralmente as previsões teóricas. Dividiu dez populações de peixes em tanques que simulavam o rio de onde haviam sido retirados. Em cinco tanques preparou o fundo com cascalho fino e outros cinco com cascalho grosso. As populações habitaram esses tanques por seis meses sem a presença de predadores, período após o qual foi observado que o número de manchas coloridas nos machos havia aumentado explosivamente, exatamente conforme a teoria havia previsto.

A seguir, dois tanques em cada grupo diferenciado pelo tipo de material no fundo receberam predadores fortes, dois receberam predadores fracos e um não recebeu qualquer tipo de predador. Passados cinco e quatorze meses todos os tanques foram recenseados e os resultados apontaram que:

a) nos quatro tanques com predadores fortes o número de manchas coloridas nos machos despencou e a intensidade das cores reduziu-se, já sendo evidente no $5^{\circ}$ mês e ainda mais no $14^{\circ}$ mês;

b) nos outros seis tanques, sem predadores ou com predadores fracos, o número de manchas continuou a aumentar até estacionar em um platô, demonstrando que, como predadores fracos não impõem uma redução significativa no número de machos, a preferência das fêmeas por "cores mais vistosas" teve maior influência na transmissão dessa característica às novas gerações;

c) nos tanques com predadores, fortes ou fracos, o cascalho grosso do fundo promoveu manchas maiores enquanto $o$ cascalho fino favoreceu manchas menores, indicando que, mesmo no caso da predação fraca, o mimetismo protegeu os animais que se confundis- 
sem melhor com o fundo do rio, permitindo-lhes que, sobrevivendo em maior número, transmitissem suas características às novas gerações;

d) nos tanques sem predadores o cascalho grosso promoveu o aparecimento de manchas menores e o cascalho fino de manchas maiores, indicando que não apenas as cores, mas também o contraste das mesmas contra o fundo, ou seja, a visibilidade dos padrões coloridos, favorecia a seleção para reprodução pela preferência das fêmeas.

Dawkins relata que, não satisfeito com os resultados, Endler repetiu o experimento isolando setores de um riacho em que era possível reproduzir as três situações retro descritas em condições naturais, e repetiu as medições de início e de evolução das populações, obtendo os mesmos resultados (DAWKINS, 2009, pp. 135 e 136). As duas séries de experimentos confirmaram todas as previsões teóricas.

Examinados esses dois exemplos de experimentos, ambos construídos em linguagem natural e destinados a testar consequências dedutíveis de teorias também construídas em linguagem natural, a conclusão é novamente contrária às afirmações de
Passeron.

\section{Conclusões}

Conforme visto, foram deduzidas três consequências das proposições de Passeron, as quais foram analisadas a partir de um procedimento simplificado (apresentação de exemplos contrários) inspirado no método de confronto empírico proposto por Karl Popper.

A análise da primeira consequência demonstrou, por meio dos exemplos apresentados, que não existe uma correlação necessária entre ciência e linguagem específica. No campo das ciências naturais, domínio inconteste das linguagens artificiais segundo Passeron, encontramos as Ciências Biológicas que, apesar de apoiarem-se na física e na química e de utilizarem extensivamente métodos quantitativos em suas pesquisas, apresenta extensas áreas em que o conhecimento é construído estrutural e essencialmente em linguagem natural. No campo das ciências sociais, domínio também incontestável da linguagem natural segundo Passeron, a economia aparece como uma ciência que se apoia cada vez mais na matemática e na estatística, as quais tem uso predominante e estrutural na econometria.

Restou afastada, assim, a proposição de Passeron, que afirma 
que as ciências têm, ou utilizam, linguagens que lhes são típicas, as quais determinam seu tipo particular de conhecimento e o tipo de prova empírica de que se valerão. Em verdade, os exemplos demonstram ampla utilização de linguagens naturais e artificiais pelos cientistas, talvez de acordo apenas com as necessidades de sua pesquisa, de seu experimento, de sua demonstração.

A análise da segunda consequência, especialmente por meio do exemplo da Teoria da Evolução por meio da Seleção Natural, de Darwin, demonstrou que a constituição de paradigmas e a realização de ciência normal, em sentido kuhniano, com o consequente acúmulo de conhecimento, exclusivamente em linguagem natural é totalmente possível. Os exemplos de outras áreas da biologia examinados apenas reforçaram tal demonstração.

Foram assim afastadas as proposições de Passeron que afirmavam que a utilização de linguagem natural - por suas ambiguidades e polissemias, por sua indexação a um contexto espaçotemporal sempre alterável, por sua baixa precisão quantitativa, etc - torna impossível acumular conhecimento em torno de um paradigma científico com ela estruturalmente construído.

A análise da terceira con- sequência foi realizada por meio de dois exemplos de experimentos, um realizado na área de psicologia cognitiva, outro na área de biologia evolutiva, que demonstram que a construção de experimentos diretos e clássicos, bem como o registro e publicação de seus resultados, em áreas do conhecimento constituídas predominantemente também em linguagem natural, é plenamente possível.

Assim, restaram também afastadas as proposições de Passeron que afirmavam que a utilização estrutural de linguagem natural por determinada ciência impede a realização de experimentos diretos em linguagem natural, restringindo a tipologia da prova empírica a serem nela utilizadas à observação sistemática.

Pode-se concluir, portanto, que a afirmação de Passeron, no sentido de que a utilização de linguagem natural nas ciências sociais cria um espaço no qual a demarcação e a refutação de uma teoria por experimentos ou observações empíricas, afirmados por Popper, e os paradigmas e a ciência normal, afirmados por Kuhn, não teriam lugar, não há de ser aceita.

As análises aqui procedidas não afirmam que o critério de demarcação de Popper ou o paradigma e a ciência normal de Kuhn são possíveis nas ciências sociais. 
Essa análise implicaria um escopo extremamente amplo e estranho ao presente trabalho. Afirma-se aqui, apenas, que a utilização de linguagem natural, por si só, não excluí a possibilidade de as ideias de Popper e Kuhn serem válidas também para as ciências sociais.

No debate sobre a unicidade do método científico, portanto, o presente artigo contribui apenas no sentido de deixar tal possibilidade em aberto, afastando as restrições construídas por Passeron, relacionadas à utilização de linguagens específicas pelas ciências, que foram aqui analisadas.

Os fatos de um paradigma não ter ainda surgido na sociologia ou de experimentos falseadores não serem extensamente utilizados ou aceitos nesse campo do conhecimento, também não significam, por óbvio, que não são possíveis: o que não foi ainda realizado ou não ocorreu talvez ainda venha a ser ou ocorrer.

Por outro lado, paradigmas e experimentos talvez não sejam mesmo possíveis nas ciências sociais. A título de exemplo, apesar de sempre ter afirmado a unicidade do método científico, o próprio Popper, reconheceu importantes diferenças entre as ciências naturais e as ciências sociais, como, por exemplo, entre as possibilidades de realização de experimentos diretos (POPPER, 1980, caps. 24 e 25), ou de aplicação de métodos quantitativos (POPPER, 1980, p. 111), ou, ainda, ao conceber a análise situacional como método típico das ciências sociais (POPPER, 1980, pp. 110 e 111 e 116 e 117).

Entretanto, sejam quais forem as eventuais razões para que a demarcação popperiana e o paradigma kuhniano não sejam eventualmente possíveis nas ciências sociais, se assim um dia se demonstrar, as conclusões do presente artigo são no sentido de que a utilização estrutural da linguagem natural nas ciências sociais não se incluirá entre elas.

\section{Referências}

BERNE, Robert M., LEVY, Mathew, KOEPPEN, Bruce, STANTON, Bruce. Fisiologia. Trad: Nephtali Segal Grinbaum e outros. Rio de Janeiro: Elsevier, 2004.

DARWIN, Charles. On The Origin of Species, em From So Simple a Begining: the four great books of Charles Darwin. Ed. by Edward O. Wilson. $1^{\text {st }}$ ed. New York: W.W. Norton \& Company, 2006. 
DAWKINS, Richard. O Maior Espetáculo da Terra: as evidências da evolução. Trad: Laura Teixeira Motta. São Paulo: Companhia das Letras, 2009.

DENNETT, Daniel C. Darwins' Dangerous Idea. New York: Simon \& Schuster, 1995.

ENDLER, John. "Natural Selection on Color Patterns in Poecilia reticulata”. In: Evolution, $\mathrm{n}^{\circ} 34,1980$, pp. 76-91. Disponível em: https://www.jstor.org/stable/2408316?seq=1\#page_scan_tab_contents. https://www.jstor.org/stable/2408316?seq=1\#page_scan_ tab_contents. Acessado em 22/11/2016.

FERREIRA, Roberto Martins. Popper e os dilemas da sociologia. São Paulo: Annablume; Fapesp, 2008.

FRANK, Robert H., BERNANKE, Ben S., JOHNSTON, Louis D. Princípios de Economia. Trad: Heloisa Fontoura e Monica Stefani. $4^{\text {a }}$ ed. Porto Alegre: AMGH, 2012.

KAHNEMAN, Daniel. TVERSKY, Amos. Julgamento sob incerteza: heurísticas e vieses. In Science, vol. 185, 1974, disponível em KAHNEMAN, 2012, pp. 524 a 539

KAHNEMAN, Daniel, Rápido e Devagar - Duas Formas de Pensar. Trad. Cássio Arantes Leite. $1^{\text {a }}$ ed. Rio de Janeiro: Objetiva, 2012.

KUHN, Thomas S. A Estrutura das Revoluções Científicas. Trad. Beatriz Vianna Boeira e Nelson Boeira. São Paulo: Perspectiva, 2009.

PASSERON, JEAN-CLAUDE. O Raciocínio Sociológico: o espaço não-popperiano do raciocínio natural. Trad. Beatriz Sidou. Petrópolis, RJ: Vozes, 1995.

POPPER, KARL R. A Miséria do Historicismo. Trad. Octanny Silveira da Mota e Leônidas Hegenberg. São Paulo: Cultrix, 1980. . A Lógica da Pesquisa Científica. Trad. Leônidas Hegenberg e Octanny Silveira da Mota. São Paulo: Cultrix, 2009.

. Popper Selections. Edited by David Miller. Princeton, Princeton University Press: 1995.

ROBBINS \& COTRAN, Patologia - Bases Patológicas das doenças. Ed: Kumar, Abbas, Fausto; Trad: Maria da Conceição Zacarias e outros. Rio de Janeiro: Elsevier, 2005. 
